\title{
Projeto de Aprendizagem Gamificado: Um Relato de Experiência
}

\author{
Anibal Lopes Guedes ${ }^{1}$ \\ ${ }^{1}$ Universidade Federal da Fronteira Sul (UFFS), \\ RS-135, 200 - Zona Rural, Erechim - RS, CEP: 99700-000, \\ anibalguedes@gmail.com
}

\begin{abstract}
This article describes an experience report from learning projects that are born from doubts and provisional certainties, in a learning gamification, with students of higher education. The research is characterized as phenomenological and exploratory. As a result of this work, the possibility of PAG as a didactic-methodological proposal to be developed in the school context is verified.
\end{abstract}

Resumo. Este artigo descreve um relato de experiência a partir de projetos de aprendizagem que nascem a partir de dúvidas e certezas provisórias, num contexto gamificado, com estudantes do ensino superior. A pesquisa caracteriza-se como fenomenológica e de cunho exploratório. Como resultado deste trabalho verifica-se a possibilidade do PAG enquanto proposta didáticometodológica a ser desenvolvida no contexto escolar.

\section{Introdução}

O projeto de aprendizagem é motivado a partir da curiosidade e do interesse dos sujeitos, além de dúvidas, incertezas e certezas provisórias sobre um determinado problema a ser investigado, podendo ser realizado de forma individual ou em grupo [Schlemmer 2002] e [Nichele 2015]. Dessa forma, os sujeitos "[...] identificam e elaboram critérios de julgamento sobre a relevância do assunto em relação a determinado contexto." [Saccol e Schlemmer e Barbosa 2011, p. 67].

[Bender 2015] propõe um conjunto de etapas para que um projeto de aprendizagem possa ser desenvolvido, entre elas:

- Definição de um tema âncora - tem como objetivo fundamentar um cenário do mundo real;

- Escolha de uma questão motriz - trata-se da problemática central ou a meta a ser atingida com o projeto de aprendizagem;

- Voz e escolha do aprendiz - os sujeitos participam de forma ativa do processo de desenvolvimento do projeto de aprendizagem. Isso inclui o poder de escolha sobre quais questões devem ser abordadas e quais as atividades a serem desenvolvidas e/ou tratadas;

- Envolve processos de investigação e pesquisa - os educadores estimulam a investigação à medida que os sujeitos avançam em seu planejamento, pesquisa e 
VII Congresso Brasileiro de Informática na Educação (CBIE 2018)

Anais do XXIX Simpósio Brasileiro de Informática na Educação (SBIE 2018)

desenvolvimento de artefatos (compreendidos enquanto as possíveis soluções ou aspectos para a solução de um dado problema);

- Envolve processos de reflexão - os projetos de aprendizagem desenvolvem diferentes habilidades (sejam elas individuais ou coletivas) em nível reflexivo em prol da seleção das melhores opções para a questão motriz;

-Necessita de feedback - baseia-se no processo de avaliação do educador, autoavaliações ou avaliações dos pares. À medida que cada sujeito amadure, torna-se importante o uso do feedback.

A partir dessas etapas, infere-se, tendo como base [Fagundes and Sato and Maçada 1999], [Schlemmer 2002] e [Bender 2015], que um projeto de aprendizagem desenvolva:

- Um trabalho cooperativo entre os envolvidos no processo;

- Enfatiza uma compreensão mais aprofundada de conteúdos, pois parte da realidade dos sujeitos;

- Estimula a construção de conhecimentos que são mais significativos aos sujeitos;

- Envolve o uso de diferentes abordagens tecnológicas para a solução dos problemas encontrados;

- Estimula a resolução de problemas;

- Predispõe a curiosidade, o desejo e a vontade do sujeito;

- Trabalha numa lógica na qual o sujeito é o agente transformador do seu processo de aprendizagem, enquanto que o educador é quem orienta e o estimula neste processo de aprendizagem.

Apoiado nesse panorama, pode-se pensar na articulação de projetos de aprendizagem num contexto gamificado enquanto possibilidade pedagógica. Dessa forma, o uso de mecânicas e dinâmicas (M\&D) de jogos podem beneficiar e enriquecer o contexto educativo.

Obviamente o tipo de projeto de aprendizagem que interessa leva em consideração o conceito de games for change, desenvolvido por [McGonigal 2012]. Trata-se de um (re)pensar na abertura das instituições de ensino (escolas, universidades, centros educacionais, entre outras) aos desafios de um engajamento criativo tanto no processo de aprendizagem quanto na própria vida dos sujeitos, levando em consideração suas realidades.

Assim, [Guedes 2017] organiza em atividades ou etapas o processo de desenvolvimento de um projeto de aprendizagem gamificado (PAG). São elas:

1. Interação com diferentes jogos (processo de investigação e pesquisa);

2. Narrativa Inicial (questão Motriz) e Definição do Escopo (âncora);

3. Estudo de diferentes abordagens tecnológicas (processos de investigação e pesquisa); 
VII Congresso Brasileiro de Informática na Educação (CBIE 2018)

Anais do XXIX Simpósio Brasileiro de Informática na Educação (SBIE 2018)

4. Desenvolvimento do PAG (voz e escolha do aprendiz com processos reflexivos e de feedback);

5. Revisão Estratégia do PAG (processos reflexivos e de feedback).

\section{Relato de Experiência}

Tendo como base os elementos teóricos que norteiam a gamificação na Educação ([Zichermann and Cunningham 2011], [McGonigal 2012], [Fardo 2013], [Schlemmer 2014] e [Guedes 2017]), nesta seção apresentam-se experiências educativas, no formato de Projetos de Aprendizagem Gamificados, desenvolvidos no curso de Pedagogia, na Universidade Federal da Fronteira Sul - UFFS, Campus Erechim.

Para tanto, se torna necessário definir o método fenomenológico. O método fenomenológico busca compreender o "mundo da vida cotidiana" [Coltro 2000, p. 38]. Este método faz uso de procedimentos que permitem entender o fenômeno por meio de relatos que descrevem a vida social.

O autor explica que "o estudo do fenômeno permite questionar e discutir os pressupostos tidos como naturais, óbvios, da intencionalidade do sujeito frente à realidade de sua ação." [Coltro 2000, p. 39].

Neste sentido percebe-se o quanto a intuição é importante, pois permite ter uma visão mais consciente do contexto em estudo, pois enfatiza a experiência do sujeito a partir de relatos pessoais. Esses relatos podem ser obtidos por meio de práticas e experiências vivenciadas [Coltro 2000]. Isso não é feito de forma meramente passiva, mas sim reflexiva.

"É por meio dessa reflexão que se dá a apropriação do nosso ato de existir, promovida por uma crítica aplicada às obras e atos - uma interpretação dos símbolos dessas obras e atos." [Coltro 2000, p. 42].

Neste caso a interpretação representa a resignificação do próprio fenômeno de forma a compreendê-lo. Além disso, a pesquisa desenvolvida tem um caráter exploratório e descritivo. A pesquisa descritiva visa desvelar um fenômeno, um fato, uma situação existente, de forma a comparar, analisar e avaliar o que vem sendo desvelado [Gil 2008].

\section{Projeto de Aprendizagem Gamificado - relato de experiência}

Esta seção tem por finalidade relatar uma experiência envolvendo a gamificação enquanto prática educativa no contexto do ensino superior a partir de Projetos de Aprendizagem Gamificados, considerados por [Guedes 2017] (descritos no item 1). Para melhor explicitar a experiência educativa optou-se pela subdivisão em subseções descritivas, conforme seguem.

\subsection{Do Público-Alvo}

O público-alvo deste relato de experiência leva em consideração estudantes do curso de Pedagogia, semestre 2017/01, do componente curricular de Tecnologias Digitais e Educação, que desenvolveram experiências significativas tendo a gamificação enquanto prática educativa. 
VII Congresso Brasileiro de Informática na Educação (CBIE 2018)

Anais do XXIX Simpósio Brasileiro de Informática na Educação (SBIE 2018)

A turma é formada por 33 estudantes, sendo que 9\% (3 estudantes) são do gênero masculino, enquanto que, 91\% (30 estudantes) são do gênero feminino. Além disso, cabe salientar que: $39,5 \%$ (13 estudantes) realizam atividades dentro do contexto educativo, trabalhando em alguma escola de educação infantil e/ou escola de ensino fundamental; 45,5\% (15 estudantes) realizam outras atividades em nível público e/ou privado; $15 \%$ (5 estudantes) apenas estudam e/ou não trabalham.

Quanto ao desenvolvimento de jogos, apenas 4 sujeitos evidenciaram desenvolver algum tipo de jogo com seus alunos e/o no âmbito empresarial, enquanto que o restante apenas faz uso de algum tipo de jogo, em sua maioria puzzles, com seus alunos e/ou no âmbito empresarial, enquanto estratégia didática.

\subsection{Interação com diferentes jogos}

A interação com diferentes jogos, sejam eles analógicos, híbridos e/ou digitais, possibilita com que os sujeitos possam interagir com diferentes dinâmicas e mecânicas de jogos, segundo [Guedes 2017].

Desse modo, os estudantes puderam experimentar e interagir com muitos estilos de jogos diferentes, entre eles: RPG, estratégia, aventura, RTS e esportes.

Em nível de tecnologia, envolviam desde jogos para computador, jogos para consoles, jogos de tabuleiro, cartas, desenhos e puzzles.

Nesta primeira etapa, observou-se o quão carente está o contexto educativo, uma vez que 29 estudantes ( $88 \%$ da amostra) desconheciam a grande maioria dos jogos apresentados, além disso, evidenciou-se que o curso de Pedagogia não dispunha de componentes curriculares que trabalhem numa perspectiva envolvendo a construção e desenvolvimento de jogos.

\subsection{Narrativa inicial e definição do escopo}

A partir da investigação e pesquisa de diferentes jogos, apresentou-se a narrativa inicial que permeará escolher uma âncora e desenvolver a questão motriz que norteará o projeto de aprendizagem gamificado.

Em vista disso, a narrativa inicial levou em consideração um videoclipe contendo a letra da música "Penso e Passo" de Alice Ruiz, como forma de instigar os futuros educadores a desenvolverem um PAG indicando o que eles mudam por onde passam.

Este videoclipe inicial, foi visto de forma inquietante e, ao mesmo tempo, permitiu com que os estudantes se organizassem em 8 clãs e pudessem refletir acerca da âncora. Dessa forma, as âncoras envolvem as seguintes temáticas: Educação Infantil e Anos Iniciais do Ensino Fundamental (50\% - 4 clãs); Anos Finais do Ensino Fundamental (13\% - 1 clã); Ensino Médio (25\% - 2 clãs) e Educação de Jovens e Adultos (13\% - 1 clã).

Já em relação à questão motriz, esta se desenrolava em questionamentos envolvendo: a vivência de sentimentos e emoções, o entretenimento, a musicalização, a teatralidade e atividades motoras. 
VII Congresso Brasileiro de Informática na Educação (CBIE 2018)

Anais do XXIX Simpósio Brasileiro de Informática na Educação (SBIE 2018)

\subsection{Estudo de diferentes abordagens tecnológicas}

De acordo com [Guedes 2017] esta etapa possibilita com que os sujeitos possam desenvolver propostas educativas por meio de diferentes tecnologias, sejam elas analógicas, digitais e/ou híbridas.

Por isso, no transcorrer do semestre do componente curricular Tecnologias Digitais e Educação, os estudantes foram convidados a "praticarem" e "desenvolverem" alguma atividade de cunho educativo envolvendo as seguintes tecnologias: Evernote (permite o desenvolvimento de diários de bordo a partir de notas e cadernos); QRDroid (permite criar e ler qrcodes a partir de diferentes mídias); Viva Video, Boomerang e Layout (permitem o desenvolvimento de vídeos); Toondoo (desenvolvimento de histórias em quadrinhos); Scratch (plataforma de programação que permite desenvolver de programas, vídeos e jogos); Spirit Fanfics (permite desenvolver histórias de fanfiction).

Tais tecnologias foram importantes, pois delinearam a etapa seguinte que culminou com o desenvolvimento do próprio PAG.

\subsection{Desenvolvimento do PAG}

O desenvolvimento do PAG de acordo com [Guedes 2017], é o elemento central de qualquer atividade gamificada. Elemento central, pois, nele é que se desenrolam as ações de um PAG que envolvem: definição do contexto e escopo; o processo de modelagem com a inclusão de narrativas, bem como os desafios e/ou missões a partir das mecânicas e dinâmicas de jogos; as influências sociais e os processos de interação; os resultados a serem atingidos.

Para facilitar o processo, considerou-se o modelo de canvas proposto por [Osterwalder 2011]. O canvas é considerado um mapa estrutural, funcionando com uma linguagem visual a fim de compreender todo o fluxo informacional de um modelo de negócios, mas que pode ser útil para quaisquer outras áreas, inclusive educacional [Osterwalder 2011].

Para fins de apresentação da estrutura desenvolvida, produziram-se vídeos digitais enquanto meios pedagógicos de apresentação das ideias de cada clã. $\mathrm{O}$ vídeo digital é entendido enquanto um instrumento interativo de mensagens audiovisuais que faz uso do computador como meio para "transmitir" a informação ao aluno, mantendo a prática pedagógica vigente [Wohlgemuth 2005]. O Fluxograma 1 mostra a estrutura gerada por um dos clãs.

Nessa lógica, os estudantes desenvolveram 8 projetos de aprendizagem gamificados, sendo que: 2 resultaram em jogos híbridos (Who I Am? e Jogo das Criações), 6 jogos analógicos que apenas utilizaram qrcodes como forma de contar a narrativa inicial e regras (Cadê?, Roda Roda, Competição Musical, Emoções, Twistter Geométrico e Educação Infantil). Todos os PAG desenvolvidos geraram como produção algum tipo de jogo. 
VII Congresso Brasileiro de Informática na Educação (CBIE 2018)

Anais do XXIX Simpósio Brasileiro de Informática na Educação (SBIE 2018)
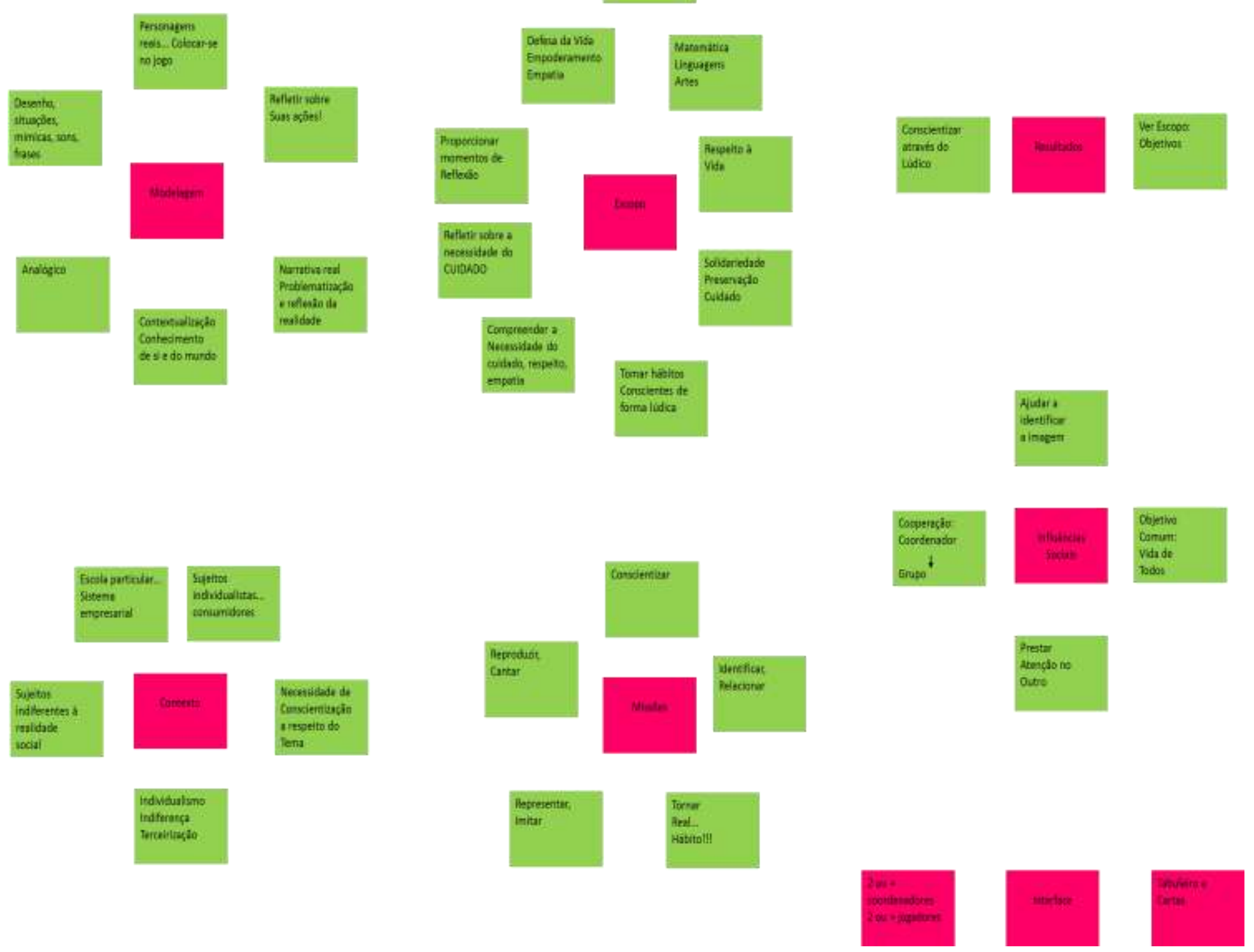

Fluxograma 1 - Clã que desenvolveu a proposta do jogo Cadê?

Fonte: Dados Primários

Os PAG Cadê?, Competição Musical, Twistter Geométrico e Emoções apoiamse numa perspectiva mais cooperativa e colaborativa entre os sujeitos, enquanto que os demais se baseiam numa perspectiva mais competitiva entre os sujeitos. A Figura 1a apresenta o jogo Cadê?, a Figura 1b apresenta jogo Who I am?, a Figura 1c apresenta o jogo Roda Roda, a Figura 1d apresenta o jogo Emoções, a Figura 1e apresenta o jogo Educação Infantil, a Figura 1f apresenta o jogo Twistter Geométrico, a Figura 1g apresenta o jogo Competição Musical e a Figura 1h representa o jogo Criações. 
VII Congresso Brasileiro de Informática na Educação (CBIE 2018)

Anais do XXIX Simpósio Brasileiro de Informática na Educação (SBIE 2018)
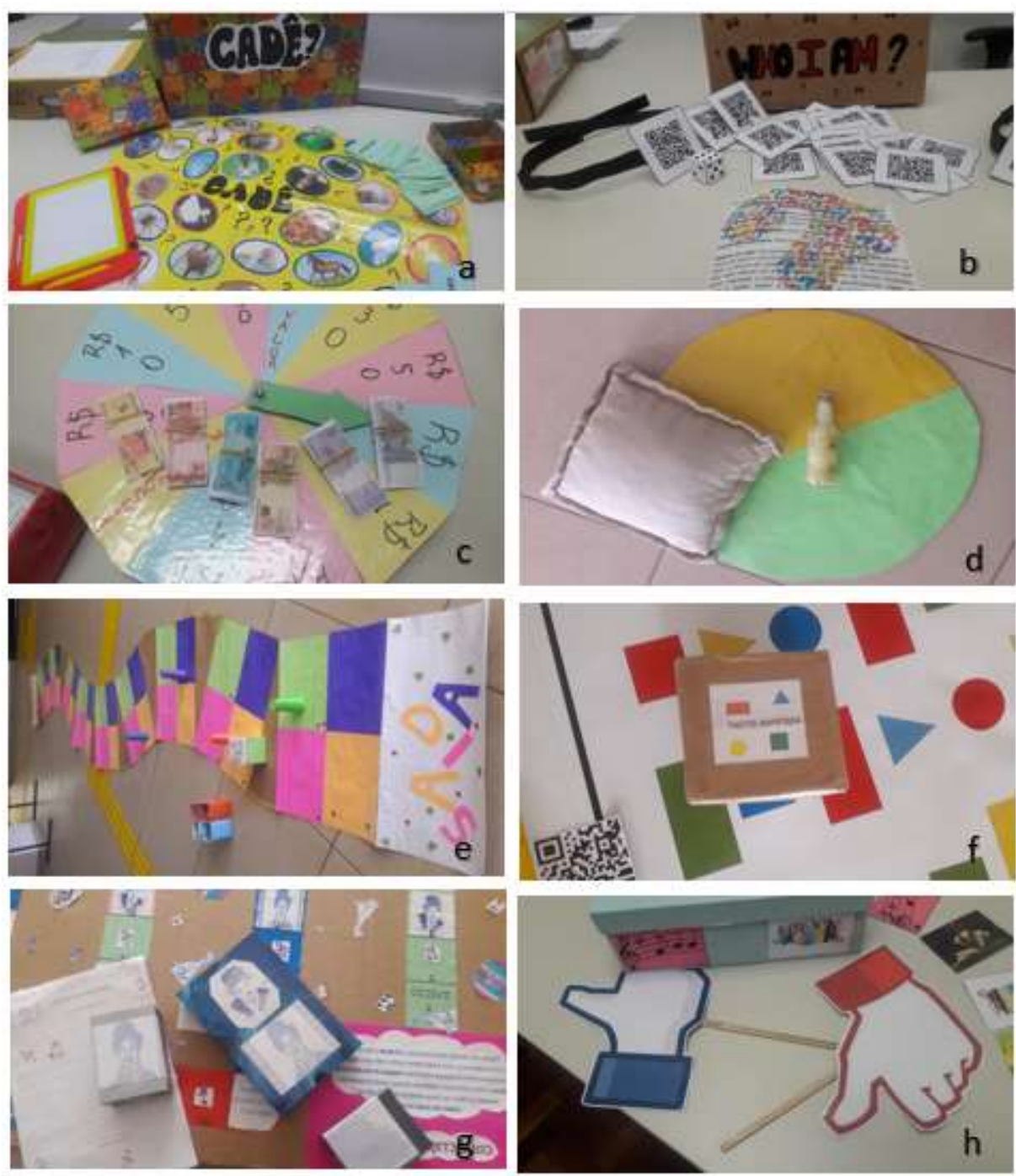

Figura 1 - Jogos Desenvolvidos

Fonte: [O Autor 2018]

Quanto às interfaces de jogos desenvolvidos, fazem uso de trilhas (Figuras 1e e 1g), dados (Figuras 1e, 1f e 1g), cartas (Figuras 1b, 1c, 1e, 1f, 1g e 1h) e outros materiais (Figuras 1a, 1b e 1d).

Pelo que se percebe, a partir dos PAG desenvolvidos que as escolhas de cada um dos aprendizes se deu a partir de seus contextos nos quais os sujeitos estão inseridos. Parte da turma, cerca de $45,5 \%$ trabalha no contexto organizacional enquanto que a parcela de sujeitos que estão em uma sala de aula enquanto apoiadores, auxiliares, contratados é de 39,5\%; o restante, $15 \%$ apenas estuda e/ou desenvolve ações a partir do PIBID (Programa Institucional de Bolsas de Iniciação à Docência), como evidenciado no item 3.1. 
VII Congresso Brasileiro de Informática na Educação (CBIE 2018)

Anais do XXIX Simpósio Brasileiro de Informática na Educação (SBIE 2018)

\subsection{Revisão Estratégia do PAG}

[Alves and Minho and Diniz 2014, p. 92], afirmam que esta etapa permite refletir e dar feedback quanto as alternativas produzidas (neste caso os PAG). Ou seja, "Reflita se a narrativa tem potencial de engajar os jogadores e está aderente às tarefas. Verifique se as tarefas são diversificadas e exequíveis e possuem regras claras. Confira se o sistema de pontuação está bem estruturado e as recompensas são motivadoras e compatíveis com o público. Verifique se todos os recursos estão assegurados e se a agenda é adequada ao público."

Dessa forma, cada clã forneceu os devidos feedbacks aos jogos produzidos por outros clãs, como forma de indicar melhorias e/ou sugestões de aprimoramento dos jogos. Entre as principais melhorias está à incorporação de qrcodes, o uso do toondoo e do scratch enquanto tecnologias digitais a serem incorporadas dentro dos jogos Cadê?, Roda Roda, Emoções e Criações.

\subsection{Considerações Parciais}

Pelo trabalho desenvolvido foi possível perceber que os jogos desenvolvidos (Roda Roda, Who I am?, Educação Infantil e Criações) estão alicerçados numa lógica persuasiva, o que, de certa forma incentiva o processo competitivo entre os sujeitos.

Verificou-se, também, que os canvas produziram vários grafos ou rizomas (a exemplo cita-se o Fluxograma 1) que possibilitaram com que os estudantes pudessem compreender e desenrolar todo o processo de concepção de cada jogo proposto pelos clãs. Falando nisso, verificou-se que dois clãs que desenvolveram os jogos Competição Musical e Criações, comportaram-se como guildas, nos quais houve a definição de papéis e de hierarquias.

Outro fato refere-se ao tipo de jogo desenvolvido, percebe-se certa "negação" dos estudantes ao desenvolvimento de jogos num estilo digital. Talvez isso seja reflexo da preferência dos estudantes a jogos no estilo analógico.

Quanto ao processo de concepção de cada jogo, estes baseiam-se na realidade na qual estão inseridos, indo de encontro ao que preconiza [McGonigal 2012] em seus ideias quanto ao games for change.

Quanto à avaliação do processo, os sujeitos relataram que a proposta foi de extrema importância uma vez que no curso de Pedagogia a questão de estímulo a produção de jogos é limitada, talvez isso seja reflexo de sua estrutura curricular.

Por fim, assim como preconiza [Guedes 2017] “[...] os sujeitos veem possibilidades não somente na gamificação, mas no uso das TD como subsidiárias deste processo de concepção de um PAG, elencando como principal artefato as tecnologias móveis".

\section{Considerações finais}

Este relato de experiência possibilita um repensar de práticas educativas a partir da proposição de projetos de aprendizagem gamificados como uma possibilidade metodológica nos processos de ensino e aprendizagem. 
VII Congresso Brasileiro de Informática na Educação (CBIE 2018)

Anais do XXIX Simpósio Brasileiro de Informática na Educação (SBIE 2018)

O uso de M\&D de jogos permitiu com que a turma ressignificasse suas práticas pedagógicas de forma a "incluir" ou "desenvolver" estratégias educativas em seus estágios dentro do contexto curricular do curso de Pedagogia. Além disso, o PAG proporcionou com que os estudantes pudessem ter contato com o canvas.

O canvas permitiu compreender melhor os processos de concepção e de desenvolvimento de cada jogo, ampliando a visão do "todo", a partir das diferentes concepções rizomáticas geradas.

Aliado a isso, os estudantes pensaram na forma de como cada "conteúdo" seria pensado e desenvolvido a partir do canvas. Com isso, percebem, assim como [Guedes 2017], que um jogo pode ser considerado um artefato ou objeto transdisciplinar, pois no contexto da Educação, como educadores "[...] necessitamos começar a praticar uma ética da e para a vida capaz de reintegrar o cosmo, a matéria, o ser humano e a vida, no sentido de resgatar o espírito de solidariedade, de respeito, de gratidão e de reverência pela vida e por todos aqueles seres que compartilham nosso destino comum. [Essa] nova cosmovisão gerada pelos avanços da ciência convoca-nos a buscar novas maneiras de ser, de viver/conviver em sociedade e com a natureza, a criar conjuntamente uma nova política de civilização [...]" [Moraes and Nava 2015, p. 30].

Por fim, o trabalho proposto permitiu vislumbrar a continuidade da pesquisa dado o interesse dos próprios estudantes nesta temática, além de desenvolvê-la em seus contextos escolares como "multiplicadores".

\section{Referências}

Alves, L. and Minho, M. R. S. and Diniz, M. V. C. (2014) "Gamificação: Diálogos com a Educação", In: FADEL, Luciane Maria; et al. (Orgs.). Gamificação na Educação. São Paulo, SP: Pimenta Cultural, p. 74-97.

Bender, W. N. (2015) “Aprendizagem Baseada em Projetos: Educação Diferenciada para o Século XXI”. Porto Alegre, RS: Penso.

Coltro, A. (2000) "A fenomenologia: Um enfoque metodológico para além da modernidade". Caderno de Pesquisas em Administração, São Paulo, SP, v. 1, n. 11, p. 37-45.

Fagundes, L. C. and Sato, L. S. and Maçada, D. L. (1999) "Projeto? O que é? Como se faz?”, In: Aprendizes do Futuro: as inovações começaram! Coleção Informática para a mudança na educação. Brasília, DF: MEC.

Fardo, M. L. (2013) “A Gamificação como Estratégia Pedagógica: Estudo de Elementos dos Games Aplicados em Processos de Ensino e Aprendizagem", 104 f. Dissertação (Mestrado em Educação) - Universidade de Caxias do Sul. Caxias do Sul, RS.

Gil, A. C. (2008) "Métodos e técnicas de pesquisa social”. 6. ed. São Paulo, SP : Atlas.

Guedes, A. L. (2017) "Emancipação digital cidadã de jovens do campo num contexto híbrido, multimodal e ubíquo", 348 f. Tese (Doutorado em Educação) - Universidade do Vale do Rio dos Sinos. São Leopoldo, RS.

McGonigal, J. (2012) “A realidade em jogo”. Rio de Janeiro, RJ: BestSeller. 
VII Congresso Brasileiro de Informática na Educação (CBIE 2018)

Anais do XXIX Simpósio Brasileiro de Informática na Educação (SBIE 2018)

Moraes, M. C. and Navas, J. M. B. (2015) "Transdisciplinaridade, Criatividade e Educação: Fundamentos ontológicos e epistemológicos." Campinas, SP: Papirus.

Nichele, A. (2015) "Tecnologias Móveis e Sem Fio nos processos de Ensino e Aprendizagem em Química: Uma Experiência no Instituto Federal de Ciência e Tecnologia do Rio Grande do Sul”, 259 f. Tese (Doutorado em Educação) Universidade do Vale do Rio dos Sinos. São Leopoldo, RS.

Osterwalder, A. (2011) "Business Model Generation: Inovação em Modelos de Negócios", Rio de Janeiro, RJ: Atlas Books.

Saccol, A. and Schlemmer, E. and Barbosa, J. (2011) "M-learning e u-learning: novas perspectivas das aprendizagens móvel e ubíqua". São Paulo, SP: Pearson Prentice Hall.

Schlemmer, E. (2002) "AVA: Um Ambiente de Convivência Interacionista Sistêmico para Comunidades Virtuais na Cultura da Aprendizagem”, $348 \mathrm{f}$. Tese (Doutorado em Informática na Educação)- Universidade Federal do Rio Grande do Sul, Porto Alegre, RS.

Schlemmer, E. (2014) "Gamificação em Espaços de Convivência Híbridos e Multimodais: Design e cognição em discussão". Revista da FAEEBA - Educação e Contemporaneidade, Salvador, BA, n. 42, v. 23, p. 73-89, jul. - dez.

Wohlgemuth, J. (2005) "Video Educativo: Uma Pedagogia Audiovisual", São Paulo, SP: SENAC SP.

Zichermann, G. and Cunningham, C. (2011) "Gamification by Design". Sebastopol, Estados Unidos: O'Reilly. 